\title{
Barbital Sodyumun Sulu Çözeltilerdeki Parçalanma Hızı Üzerinde Sakkaroz Konsantrasyonunun Etkisinin Incelenmesi
}

The Influence of Concentration of Saccharose on The Rate of Degradation of Barbital Sodium in Aqueous Solutions

Enver IZGU*
Ilbeyi AĞABEYOĞLU*

\section{GIRiș}

Barbitürik asit ilk defa 1864 de von BAEYER tarafindan sentez edilmiştir. Bu gurup bileşiklerin hipnotik olarak ilk kullanılanı barbital olup, VERONAL ticari adıyla FISCHER ve von MERING tarafindan piyasaya 1903 yılında sürülmüştür. Takip eden yıllarda 2500 den fazla barbitürik asit türevi sentez edilip, farmakolojik olarak incelenmiş ve klinik kullanma için piyasaya yaklaşı 50 türev sürülmüştür. Bugün hali hazırda yaklaşık 12 kadarı yaygın olarak kullanılmaktadır (1). Yapılan araştırmalara göre, bazı ilaçların metabolizmalarını barbitürik asit türevlerinin hızlandırdığı saptandığından, kullanılmaları ayrı bir önem kazanmıştır (2).

Barbitürik asit türevlerinin stabiliteleri üzerinde bugüne kadar çeşitli araştırmalar yapılmıştır $(3,4,5,6,7)$. Sulu ortamda, özellikle alkali $\mathrm{pH}$ larda bozunma artar. Barbitalin yüksek $\mathrm{pH}$ lardaki degradasyon ürünleri sırasıyla, dietilmalonürik asit, dietilasetilüre, dietilasetik asit, amonyak ve karbonattır $(3,5,6,7,8)$.

Barbitürik asit türevleri, yapılarındaki karbonil gurubuna iki yönden bağlı azotlar ve $-\mathrm{CH}_{2}$ gurubundaki hidrojenlerden dolay1 yeter derecede asit olup, alkalilerle tuz teşkil ederler (8). Bu tuzların

Redaksiyona verildiği tarih: 16 Ocak 1976

(*) Farmakognozi ve Galenik Farmasi Kürsüsü, Eczacılk Fakültesi, Ankara Úniversitesi. 
sulu çözeltilerinin $\mathrm{pH}$ sı belirli bir değerin altına inerse, noniyonize şekilde barbitürik asit kısmı çöker.

Barbitürik asit türevlerinin çözünürlüğü ve dayanıklılığını arturmak için enjeksiyonluk çözeltileri dimetilformamit, dimetilasetamit ve propilen glikol gibi organik çözücülerle hazırlanır. HUSA, fenobarbital sodyumun dayanıkhlığını artıran maddeler olarak şunlanı vermiştir: Alkoller, glikoller, paraldehit, gliserol, üretan, üre, metanamin, propilen glikol ve çeşitli amin ve amitler (3).

Barbitüratların stabilitesi üzerindeki bu geniş çalı̧̧malara rağmen, oral çözeltilerdeki sakkaroz konsantrasyonunun parçalanmadaki etkisi üzerinde fazla durulmamıştır.

Biz bu çalışmada, Barbital Sodyumun değişik sakkaroz konsantrasyonlarında bozunmasını ve genellikle kullanilan bir konsantrasyonda hızlandırılmış stabilite testiyle $\mathrm{pH}$ nun etkisini inceledik.

\section{MATERYAL VE YÖNTEM}

Gereçler: Kullanılan maddelerden Barbital Sodyumun, sodyum klorür, sodyum hidroksit E. Merck, Darmstadt; primer ve sekonder sodyum fosfatlar Riedel-de Haen kaynaklıdır. Sakkaroz ise, "Türkiye Şeker Fabrikaları, Ankara"'nın Kristal Şeker isimli ürünüdür. Erlenler Teknik Cam'dır. Kullamilan banyolar, Grant Instruments (Cambridge), Ingiltere ve VEB MLW Prüfgeraete-Werk, D. Almanya'dır. Spektrofotometre ise, Pye-Unicam'in SP 1700 modeli olup, AR-25 Recorder'ın içerir. Kullanılan $\mathrm{pH}$ metreler ise, Orion Model 701 digital ve Beckman $\mathrm{H} 4$ dür.

Yöntem: Barbital Sodyumun $10^{-2} \mathrm{M}$ konsantrasyonda distile sudaki çözeltisi stok olarak hazırlanıp, buzdolabında saklandı.

Tablo I de verilen tamponlar yeni çekilmiş distile su ile hazırlandı. Bütün tamponlarda gereken durumlarda iyon kuvveti $\mathrm{NaCl}$

Tablo I, Kullanilan Tamponlar

\begin{tabular}{|r|c|c|c|c|c|c|}
\hline $\mathrm{pH}$ & $\begin{array}{c}\mathrm{NaH}_{2} \mathrm{PO}_{4}, \\
2 \mathrm{H}_{2} \mathrm{O}\end{array}$ & $\begin{array}{c}\mathrm{Na}_{2} \mathrm{HPO}_{4} \\
12 \mathrm{H}_{2} \mathrm{O}\end{array}$ & $\mathrm{NaHCO}_{3}$ & $\begin{array}{c}\mathrm{Na}_{2} \mathrm{CO}_{3} . \\
\mathrm{H}_{2} \mathrm{O}\end{array}$ & $\mathrm{NaOH}$ & $\mathrm{NaCl}$ \\
\hline 7.1 & $9.7518 \mathrm{~g}$ & $37.2498 \mathrm{~g}$ & - & - & - & $0.0292 \mathrm{~g}$ \\
8.8 & - & - & $3.3774 \mathrm{~g}$ & $0.4960 \mathrm{~g}$ & - & $5.3774 \mathrm{~g}$ \\
10.2 & - & - & $0.9745 \mathrm{~g}$ & $4.7864 \mathrm{~g}$ & - & $1.3210 \mathrm{~g}$ \\
11.6 & - & - & - & - & $2.000 \mathrm{~g}$ & $5.8450 \mathrm{~g}$ \\
11.8 & - & - & - & - & $4.000 \mathrm{~g}$ & $2.9225 \mathrm{~g}$ \\
12.0 & - & - & - & - & $6.000 \mathrm{~g}$ & - \\
\hline
\end{tabular}


ile 0.15 e ayarland,. Deneye göre gerekli miktarlarda sakkaroz, ilgili tampon içinde oda sıcaklığında karıştırılarak eritildi. G3 cam filtresinden süzüldü. $\mathrm{Bu}$ çözeltiden referans olarak kullanılmak üzere bir miktar ayrıldı, Kalan çözelti üzerine $10^{-4} \mathrm{M}$ olacak şekilde barbital sodyum stok çözeltisinden ilave edildi. Yaklaşık iki saat oda sıcakliğında bekletildi. UÇ̧ adet $100 \mathrm{ml}$ lik erlene kondu. Referans çözelti de, aynı tip erlene konarak belirli sıcaklığa getirilmiş sıvı parafin banyolarina oturtuldu ( $\mp 1 \mathrm{G}^{\circ}$ ). Çeşitli zaman aralıklarında numuneler alınıp, $\mathrm{pH}$ ları $\mathrm{N} \mathrm{NaOH}$ çözeltisiyle yaklaşık 11.5 a getirilip, spektrofotometrede $238 \mathrm{~nm}$ deki absorbans değerleri okundu. Üç erlendeki değerlerin ortalaması alınarak o süreye ait absorbans saptandı. Alınan numunelerin aynı zamanda $\mathrm{pH}$ ları da ölçüldü. $\mathrm{pH}$ metrelerin ayarı, ilgili sıcaklığa önceden getirilmiş tampon çözeltilerle yapilds.

Kinetik Incelemeler: Hazırlanan çözeltilerin bir kere deney başında ve sonra da deney boyunca çeşitli zaman aralıklarında spektrofotometrede absorbansları, A, ölçüldü. Bundan sonra,

$$
\ln \mathrm{A}=\ln \mathrm{A}_{0}-\mathrm{kt}
$$

denklemine göre grafikleri çizildi (Şekil 1, 2, 4). Oluşan doğrunun eğimi En Küçük Kareler Metoduna göre hesaplandı (9). Buradan,

$$
\mathrm{k}=- \text { eğim }
$$

bağıntısından reaksiyon hız sabiteleri hesaplandı, Bundan sonra reaksiyon yarı ömrü şu denklemle bulundu:

$$
\mathrm{t}_{1 / 2}=\frac{\ln 2}{\mathrm{k}}=\frac{0.693}{\mathrm{k}}
$$

pH nın Etkisi: $60^{\circ} \mathrm{C}$ sıcaklıkta ve $\% 10$ a/h sakkaroz ile değişik $\mathrm{pH}$ larda deneyler tekrarlanarak, yukarıda anlatılan şekilde, reaksiyon hiz sabiteleri bulundu.

Spesifik Baz Katalizi gösteren bir maddenin bozulması şu denklemle belirlenmektedir (10):

$$
\log \mathrm{k}=\mathrm{pH}+\log \left(\mathrm{k}_{\mathrm{oH}} \mathrm{xK}_{\mathrm{SU}}\right)
$$

Burada $k$, izlenen reaksiyon hyz sabitesi, $\mathrm{k}_{\mathrm{OH}^{-}}$, hidroksil iyonlarının birleşme hız sabitesi ve $\mathrm{K}_{\mathrm{su}}$ ise, suyun denge sabitesidir. Dolayısıyla, $\mathrm{pH}$ ya göre $\log \mathrm{k}$ nın grafiği çizildiğinde, eğimi 1 olan bir doğru elde edilecektir. 
Sıcaklığın Etkisi: Arrhenius denklemine göre reaksiyon hiz sabitesiyle sıcaklık arasındaki ilişki şöyledir:

$$
\ln \mathrm{k}=\ln \mathrm{P}-\frac{\mathrm{E}_{a}}{\mathrm{R}} \cdot \frac{1}{\mathrm{~T}}
$$

Burada $\mathrm{E}_{a}$, Aktivasyon Enerjisi ve $\mathrm{P}$ de Frekans Faktörüdür. Dolayısıyla ln k ordinata ve I/T de absise gelecek şekilde hazırlanan grafiğin eğimi $-\mathrm{E}_{A} / \mathrm{R}$ ye eşit olacağından (Şekil 5), aktivasyon enerjisi buradan hesaplandı. Bu doğrunun ordinatı kestiği nokta ln P ye eşittir. Diğer taraftan Aktivasyon Entropisi $\triangle \mathrm{S}_{a}$, şu denklemle hesapland1:

$$
\Delta \mathrm{S}_{a}=\mathrm{R}\left(\ln \mathrm{P}-\ln \frac{\mathrm{kT}}{\mathrm{h}}\right)
$$

Burada R, gaz sabitesi (1.987 cal/mol. derece), k, Boltzmann sabitesi $\left(1.38 \times 10^{-16} \mathrm{erg} /\right.$ derece $)$ ve $\mathrm{h}$ da Planck sabitesidir (6.63 $\times 10^{-27}$ erg.saniye).

\section{SONUÇLAR}

Sakkaroz Konsantrasyonunun Dayanıklılık Üzerine Etkisi: Barbital sodyumun sulu çözeltilerdeki dayanıklılığına sakkaroz konsantrasyonunun etkisini incelemek için yaptığımız deneylerin koşulları ve sonuçları Tablo II ve Şekil 1 de gösterilmiştir:

Tablo II. Sakkaroz Konsantrasyonunun Etkisi

\begin{tabular}{|c|c|c|c|c|}
\hline $\begin{array}{c}\text { Sakkaroz } \\
\text { miktarı }(\%)\end{array}$ & $\begin{array}{c}\text { Sicaklık } \\
\left({ }^{\circ} \mathrm{C}\right)\end{array}$ & $\mathrm{pH}$ & $\begin{array}{c}\text { Reaksiyon hiz } \\
\text { sabitesi }\left(\mathrm{sn}^{-1}\right)\end{array}$ & $\begin{array}{c}\text { Yarı ömür } \\
\text { (gün) }\end{array}$ \\
\hline 0 & 60 & 7.1 & $3.36 \times 10^{-7}$ & 24 \\
10 & $"$, & $1.39 \times 10^{-7}$ & 58 \\
20 & $"$, & $0.977 \times 10^{-7}$ & 82 \\
40 & $"$, &, & $0.746 \times 10^{-7}$ & 107 \\
60 & $"$, &, & $0.412 \times 10^{-7}$ & 195 \\
\hline
\end{tabular}

pH nın Dayanıklılı Üzerine Etkisi: pH nın barbitalin stabilitesi üzerine olan etkisini gösteren deneyler ve sonuçlan Tablo III ve Şekil 2 ve 3 de görülmektedir.

Sıcaklığın Etkisi: Değişik sıcaklıklarda yapılan deneyler ve sonuçları Tablo IV ile Şekil 4 ve 5 de görülmektedir. 


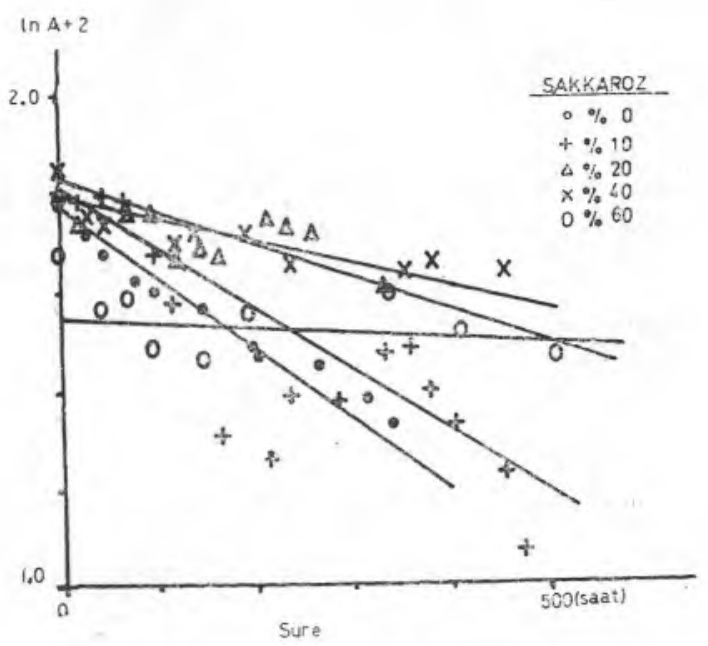

Şek. 1. Değişik konsantrasyonlarda sakkaroz içeren barbital çözeltilerinin zamana bağlı olarak $238 \mathrm{~nm}$ deki absorbanslarının değișmesi.

Tablo III. pH'nun Etkisi

\begin{tabular}{|c|c|c|c|c|}
\hline $\begin{array}{l}\text { Sakkaroz } \\
\text { miktar1(\%) }\end{array}$ & $\begin{array}{l}\text { Sicaklık } \\
\left({ }^{\circ} \mathrm{C}\right)\end{array}$ & $\mathrm{pH}$ & $\begin{array}{l}\text { Reaksiyon hiz } \\
\text { sabitesi }\left(\mathrm{sn}^{-1}\right)\end{array}$ & $\begin{array}{l}\text { Yarı ömür } \\
\text { (gün) }\end{array}$ \\
\hline $\begin{array}{l}10 \\
", \\
" \\
"\end{array}$ & $\begin{array}{l}60 \\
\text { ", } \\
\text { ", } \\
\text { ", }\end{array}$ & $\begin{array}{r}7.1 \\
8.8 \\
10.2 \\
11.6 \\
11.8 \\
12.0\end{array}$ & $\begin{array}{c}1.39 \times 10^{-7} \\
12.0 \times 10^{-7} \\
23.0 \times 10^{-7} \\
96.7 \times 10^{-7} \\
198 \times 10^{-7} \\
239 \times 10^{-7}\end{array}$ & $\begin{array}{l}58 \\
6.7 \\
3.5 \\
0.83 \\
0.41 \\
0.34\end{array}$ \\
\hline
\end{tabular}

Denklem 5 e göre çizilen doğrunun eğimi (Şekil 5) ve ordinatı kestiği nokta, En Küçük Kareler Metodu'na göre hesaplandi. Denklem 6 yardımıyla da Aktivasyon Entropisi bulundu. Sonuçlar Tablo $\mathrm{V}$ de yer almaktadır $\left(80^{\circ} \mathrm{C}\right.$ ve $\left.\mathrm{pH} 11.6 \mathrm{da}\right)$.

TARTIŞMA

Sakkaroz Konsantrasyonunun Dayanıklılı Üzerine Etkisi: Şekil 1 den görüldüğü gibi, barbital sodyumun sulu çözeltilerinin absorbanslarının logaritmaları zamana göre çizildiğinde bir doğru elde edilmektedir. Buna göre bozunma reaksiyonu birinci 
dereceden oluşur gözükmektedir. Esasen bu bulgu literatürü desteklemektedir (6).

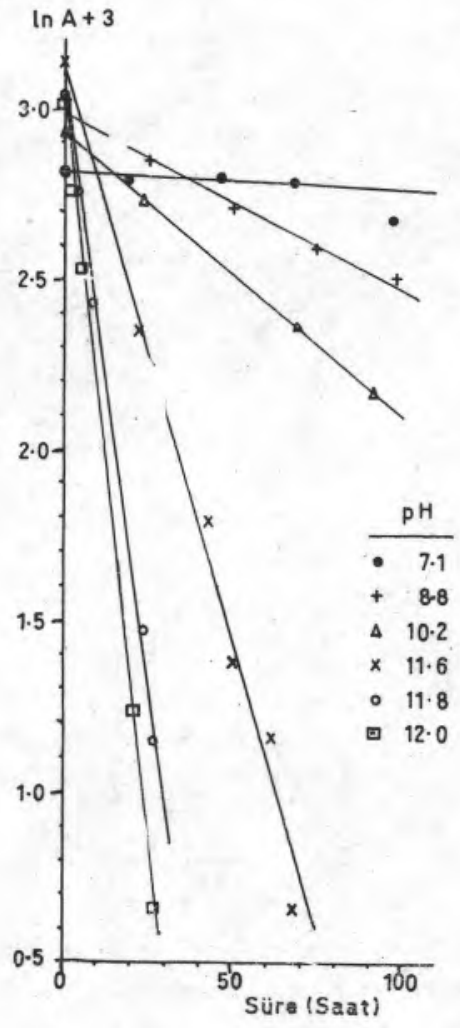

Şek. 2. $\% 10$ sakkaroz içeren, $60^{\circ} \mathrm{C}$ deki barbital çözeltilerinin değişik $\mathrm{pH}$ larda zamana bağlı olarak $238 \mathrm{~nm}$ deki absorbanslarının değişmesi.

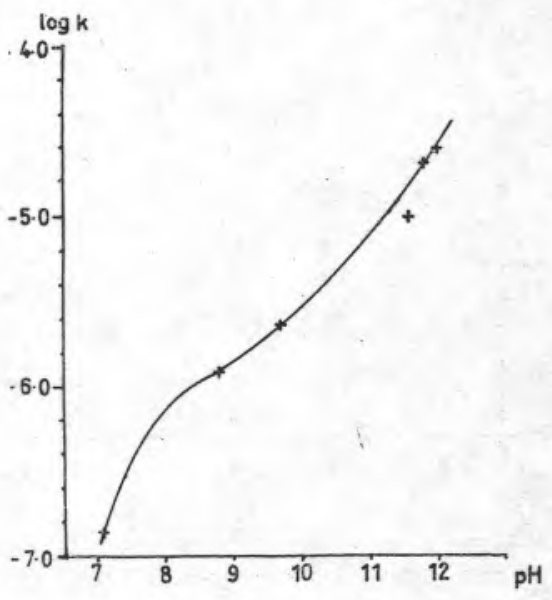

Şek. 3. $\% 10$ sakkaroz içeren, $60^{\circ} \mathrm{C}$ deki barbital çözeltilerinin $\mathrm{pH}$ ya bağlı olarak reaksiyon hiz sabitelerinin değişmesi.

Tablo IV. Sıcaklığın Etkisi

\begin{tabular}{|c|c|c|c|c|}
\hline $\begin{array}{l}\text { Sakkaroz } \\
\text { miktari(\%) }\end{array}$ & $\begin{array}{l}\text { Sicakllk } \\
\left({ }^{\circ} \mathbf{C}\right)\end{array}$ & $\mathrm{pH}$ & $\begin{array}{l}\text { Reaksiyon hiz } \\
\text { sabitesi }\left(\mathrm{sn}^{-1}\right)\end{array}$ & $\begin{array}{l}\text { Yar1 ömür } \\
\text { (saat) }\end{array}$ \\
\hline $\begin{array}{l}10 \\
, "\end{array}$ & $\begin{array}{l}60 \\
70 \\
80\end{array}$ & $\begin{array}{l}11.6 \\
",\end{array}$ & $\begin{array}{l}96.7 \times 10^{-7} \\
221 \times 10^{-7} \\
411 \times 10^{-7}\end{array}$ & $\begin{array}{l}20 \\
8.7 \\
4.7\end{array}$ \\
\hline
\end{tabular}




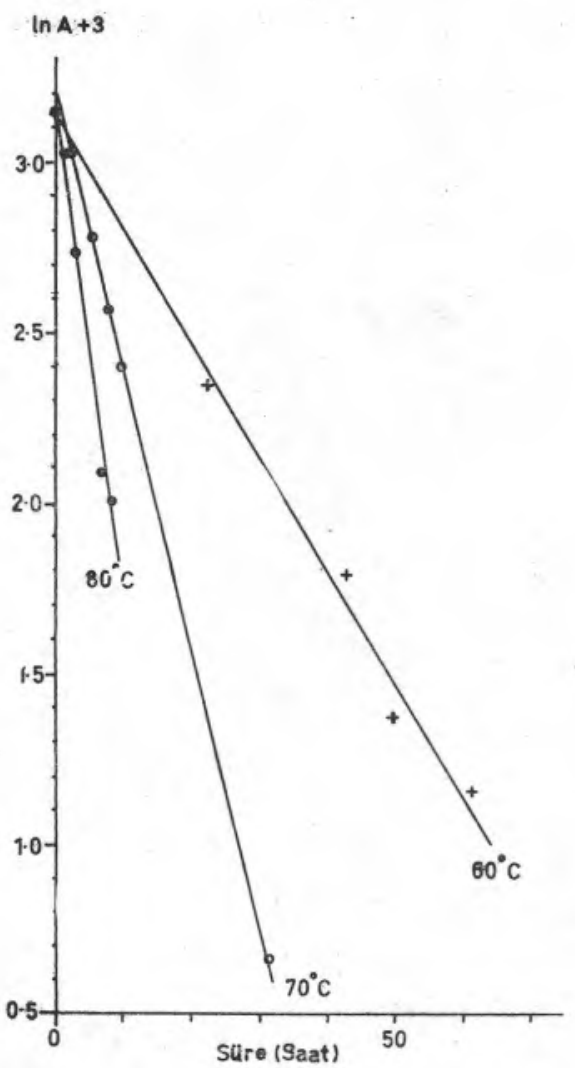

Şek. 4. \% 10 sakkaroz içeren ve $\mathrm{pH} 11.6$ daki değişik sıcaklıklardaki barbital çözeltilerinin $238 \mathrm{~nm}$ deki absorbanslarının zamanla değişmesi.

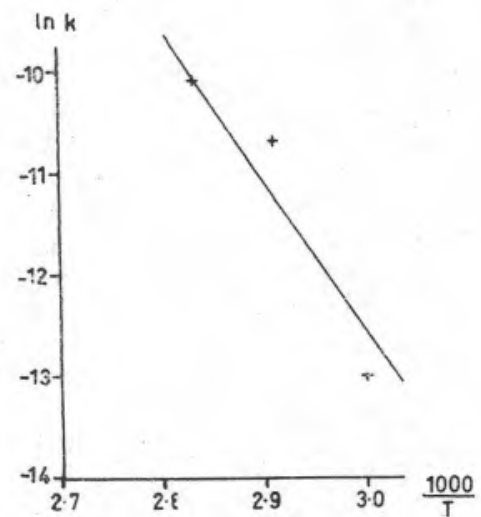

Şek. 5. \% 10 sakkaroz içeren ve $\mathrm{pH} 11.6$ daki barbital çözeltilerinin reaksiyon hız sabitelerinin $1 / \mathrm{T}$ ye göre değişmesi

Tablo V. Termodinamik Parametreler

\begin{tabular}{|l|l|}
\hline $\mathrm{E}_{\mathrm{a}}$ & $34.2 \mathrm{kcal} / \mathrm{mol}$ \\
$\ln _{\mathrm{P}}$ & 38.9 \\
$\mathrm{P}$ & $8.19 \times 10^{22} \mathrm{sn}^{-2}$ \\
$\triangle \mathrm{S}_{\mathrm{a}}$ & $18.5 \mathrm{e.b}$. \\
\hline
\end{tabular}

Görüldüğü gibi, ortamdaki sakkaroz miktarı arttıkça bozunma azalmakta ve dayanıklılık artmaktadır. Ortama ilấve edilen sakkaroz \% 10 gibi düşük bir değerde bile olsa, iki misli dayanıklılık elde edilmektedir. Daha yüksek oranlarda da bu etki görülmektedir. 
Sakkaroz miktariyla reaksiyon hiz sabitesi arasındaki korelasyon katsayısını hesaplayınca (9) bu değeri -0.811 olarak bulduk. Dolayısiyla ortada-belirli sınırlar içinde kalmak üzere -negatif doğrusal bir korelasyon vardır. Esasen sakkarozun artmasiyla hiz sabitesinin azalması da bu durumu açıkca kanıtlamaktadır.

pH nın Dayanıklılık Üzerine Etkisi: Tablo III ve Şekil 1 ile 3 de görüldüğü gibi barbital, ortamın $\mathrm{pH}$ sı arttıkça daha çabuk parçalanmaktadır. Reaksiyon hız sabitelerinin büyümesi ve yarı ömrün kısalması bunu kanıtlamaktadır. Şekil 3 de, $\mathrm{pH} 10$ un üzerinde spesifik baz katalizi görülmektedir. Eğrinin bu kısmının eğimi hesaplanınca 0.982 bulundu. Denklem 4 e göre tecrik 1 değerine çok yakın bir değerdir. Dolayısiyla ortamda gerçekten bir baz katalizi yeralmaktadir.

Sıcaklığın Etkisi: Değişik sıcaklıklarda yapılan deneyler ve bunların sonuçlarına göre yapılan hesaplara göre Aktivasyon Enerjisi mol başına 34,2 kcal olarak bulundu ( $\% 10$ sakkaroz içeren çözeltide). GARRET ve arkadaşları (6) barbital için bu değeri 18,2 $\mathrm{kcal} / \mathrm{mol}$, GOYAN ve arkadaşları (4) ise, $16.2 \mathrm{kcal} / \mathrm{mol}$ olarak bulmuşlardı. Dolayısıyla sakkarozun bulunduğu ortamda barbitalin bozulma olasılığı daha azalmaktadır.

Diğer taraftan, aktivasyon entropisinin pozitif olması, ortamda bir zincirleme reaksiyon bulunduğunu kanitlamaktadır (11). Esasen durumun böyle olduğu önceden de bilinmektedir. $(3,5,6,7,8)$.

\section{ÖZET}

Biz bu çalş̧mada barbital sodyumun sulu çözeltilerine ilave edilen sakkarozun barbitalin dayanıklılığı üzerine olan etkisini kinetik yönden inceledik.

Bulgularımıza göre bozunma, sakkaroz miktarının artmasına paralel olarak azalmaktadır.

Diğer taraftan aynı sakkaroz konsantrasyonunda ortamın $\mathrm{pH}$ sının artmasıyla parçalanma daha fazla olmaktadır.

Ortam sıcaklı̆ı̆ın artması da aynı koşullarda barbitalin bozulmasın hizlandırmaktadır. 


\section{SUMMARY}

An investigation was made of the influence of the concentration of saccharose on the stability of barbital sodium in aqueous solutions.

The stability of barbital sodium was found to be increased with the increasing concentration of saccharose (Table II, Figure 1).

The experimentally determined Energy of Activation was approximately twice as great as a system containin no saccharose, as was reported in the literature $(4,6)$. The Entropy of Activation was found to be positive (Table V).

Specific base catalysis was taking place, especially at higher $\mathrm{pH}$ values; increasing the degradation of barbital.

The increase of temperature was enhancing the degradation rate of the substance under similar conditions (Figures 4,5 and Table IV).

T e şek k ü r : Spektrofometre olanaklarından yararlandiğımız Farmasötik Kimya Kürsüsüne teşekkür ederiz.

\section{LITERATƯR}

1. Sharpless, S. K., "Hypnotics and Sedatives, I. The Barbiturates". Goodman, L.S., Gilman, A., Eds., -The Pharmacological Basis of Therapeutics. 4th. Ed., The Macmillan Co., U.S.A. 98 (1970).

2. İzü, E., Dirim, 46, 435 (1971).

3. Husa, W.J., Jatul, B.B., Jour,Am.Pharm.Ass.Sci.Ed., 33, 217 (1944).

4. Goyan, J.E., Shaikh, Z.I., Autian, J., ibid., 49, 627 (1960).

5. Tishler, F., Sinsheimer, J.E., Goyan, J.E., J.Pharm.Sci., 51, 214 (1962).

6. Garrett, E.R., Bojarski, J.T., Yakatan, G.J., ibid., 60, 1145 (1971).

7. Rotondaro, F.A., Gour.Assoc.Off.Agric.Chem., 23, 777 (1940).

8. Amâl, H.,-Farmasötik Kimya II, Organik kısım, ikinci baskı, İtanbul Ùniversitesi Yayınları No: 915, 285. (1961).

9. Spiegel, M.R., -Theory and Problems of Statistics, Schaum Pub. Co., New York, U.S.A. 220 (1961).

10. Martin, A.N., Swarbrick, J., Gammarata, A.,-Physical Pharmacy, 2 nd. Ed., Lea and Febiger, Philadelphia, U.S.A. 384 (1969).

11. Berkem, A.R., -Modern Fizikokimya, İstanbul Üniversitesi Yayınları No: 1779,403 (1972). 